\title{
Experiences with AR plots: design issues and recommendations for augmented reality based mobile games
}

\author{
Dan Dixon, Saad Liaquat Kiani* and Ahsan Ikram
}

\author{
*Correspondence: \\ saad2.liaquat@uwe.ac.uk \\ Faculty of Engineering and \\ Technology, University of the West \\ of England, Coldharbour Lane, \\ Bristol, BS16 1QY, UK
}

\begin{abstract}
Digital games have the potential for changing attitudes towards social issues such as climate change and sustainability. This paper presents the experience of developing a prototype locative game with an augmented reality interface that is designed to fit in with the fractured nature of travel time on public transport. We discuss the technical challenges, usability issues and game design approaches used to work within these constraints.
\end{abstract}

\section{Introduction}

This paper outlines the early stage results of developing a location-based game with an augmented reality (AR) interface ${ }^{\mathrm{a}}$. The game's system architecture is shown in Figure 1. The game 'AR Plots' is intended to be played on local, intra-city bus trips and carry a message about climate change and sustainability. This is part of a wider project to examine how technology can instrumentally affect people's attitudes towards climate change and sustainability issues.

In AR Plots the players grow plants alongside bus routes, watering their own and friends' plots. Virtual gardens grow up by bus stops and traffic lights. When the bus stops for a length of time, empty plots are created that they or other players can plant in. A player can plant a seed in a plot and then 'owns' it with their plant. Plants need watering, however the amount of water they have is limited. Plants only bear fruit or flowers if other players also water them. A simple one-click 'check in' mechanism is used for the players to water their own or other's plant. Figures 2 and 3 show snapshots of the game's graphical interface. Augmented reality is the basis for the graphical interface and has been prototyped and tested on Android smart phones, using a background service and the Layar AR browser [1]. The game is designed to work on Bristol, UK, based buses intended for a commuter audience.

The game design and interaction faced a number of constraints due to limitations in software and hardware platform as far as interactive AR gaming is concerned. The GPS accuracy is variable and effects placements of digital artefacts in the virtual world and also the detection of stoppages and movements of the device. Different device screen sizes affect the quality of interactive experience of users. Moreover, Layar limits the actions that

(C) 2013 Dixon et al.; licensee Springer. This is an Open Access article distributed under the terms of the Creative Commons

Attribution License (http://creativecommons.org/licenses/by/2.0), which permits unrestricted use, distribution, and reproduction in any medium, provided the original work is properly cited. 


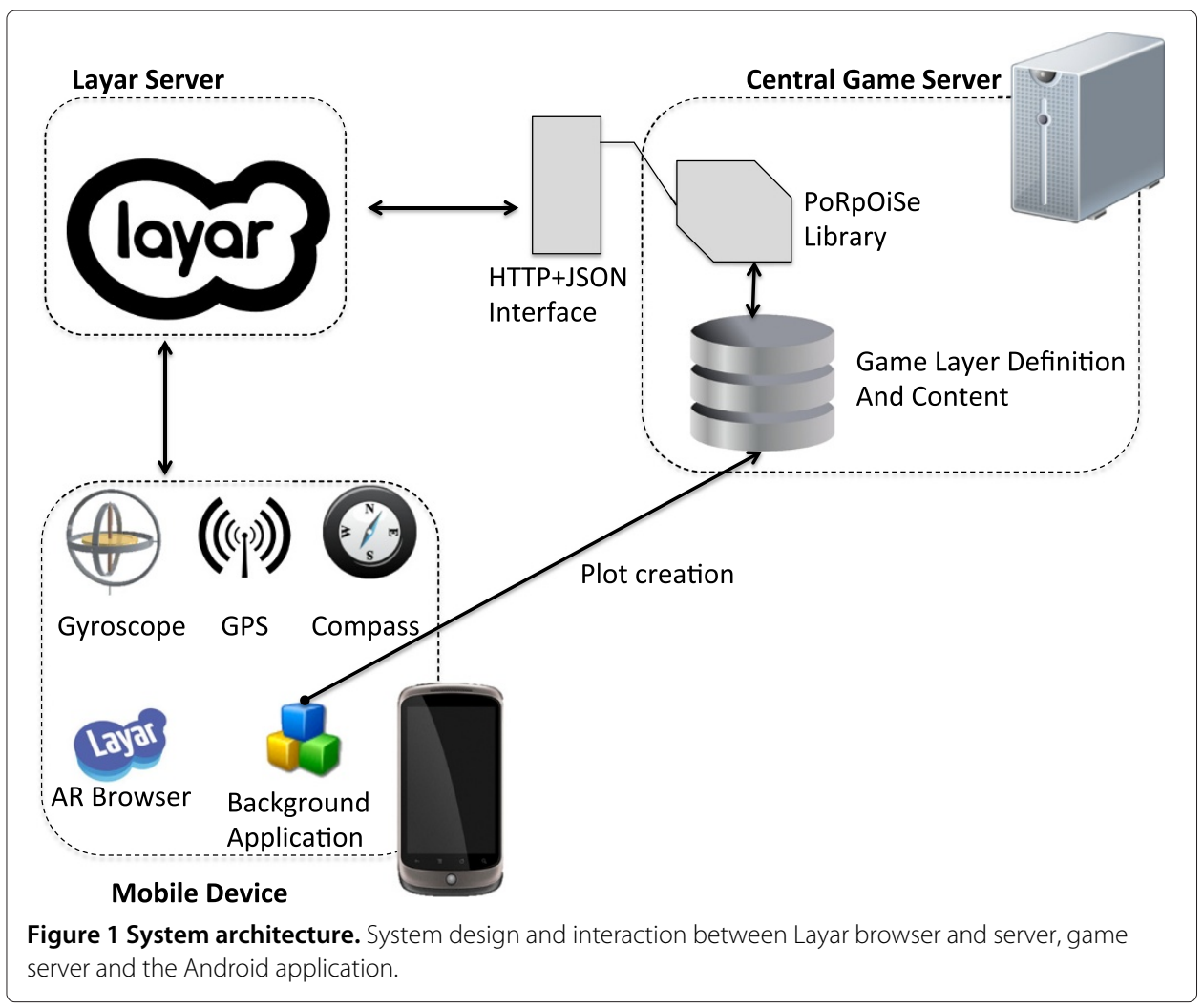

can be performed by interacting with the digital objects in the augmented reality view i.e. actions are predefined on the central server and cannot be modified dynamically based on user actions.

\section{Interface constraints and context for use}

To understand the issues for designing a game with Layar as the platform, a PACT analysis framework [2] was used to evaluate the application in the context that the game will be played; on local buses in Bristol. The small-scale project utilised discount usability [3] and iterative design. Early stage prototypes were evaluated in live situations by the extended project team, which highlighted the following key issues:

\section{Motion sickness whilst using an AR browser}

All participants reported a feeling of motion sickness whilst interacting with the Layar based game, including those who didn't normally feel motion sick whilst reading or using devices in vehicles. It appears that the overlay of information in Layar's camera view brings about the feelings of nausea, which quickly subside when not using Layar. Motion sickness is still a poorly understood physiological phenomenon but the stimuli that cause it are well documented. These causes are usually isolated to either inertial motion sickness or visually induced sickness $[4,5]$.

\section{Social issues of camera use}

Another observation was that when the phone is held up, people in front of the camera are very aware of being photographed or filmed. The pointing of cameras raises two interrelated issues of privacy [6] and the claiming of personal social 


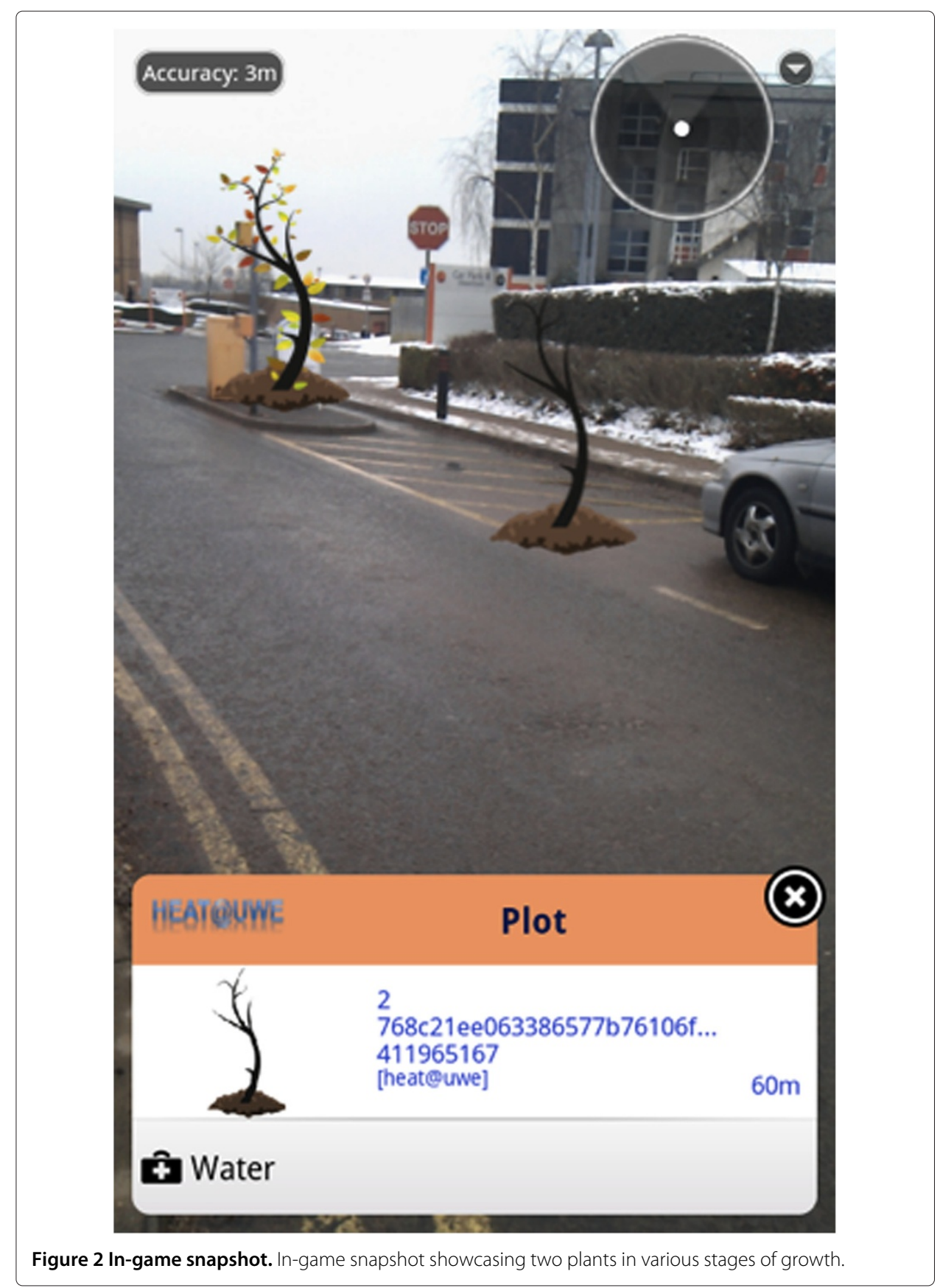

space [7]. The user can be seen to be claiming a particular, indeterminate space and bringing in-view people into a one way, non-negotiated relationship. This makes the users uncomfortable, as well as other people on the bus, creating a very difficult situation for the use of this technology whilst on any forms of public transport.

\section{Device and interface issues}

There are two specific device issues that came up during testing. First, the lighting on a bus is highly variable, based on the internal lighting and the level of sunlight coming in from the outside, and can affect the experience. Secondly, there is a lag 


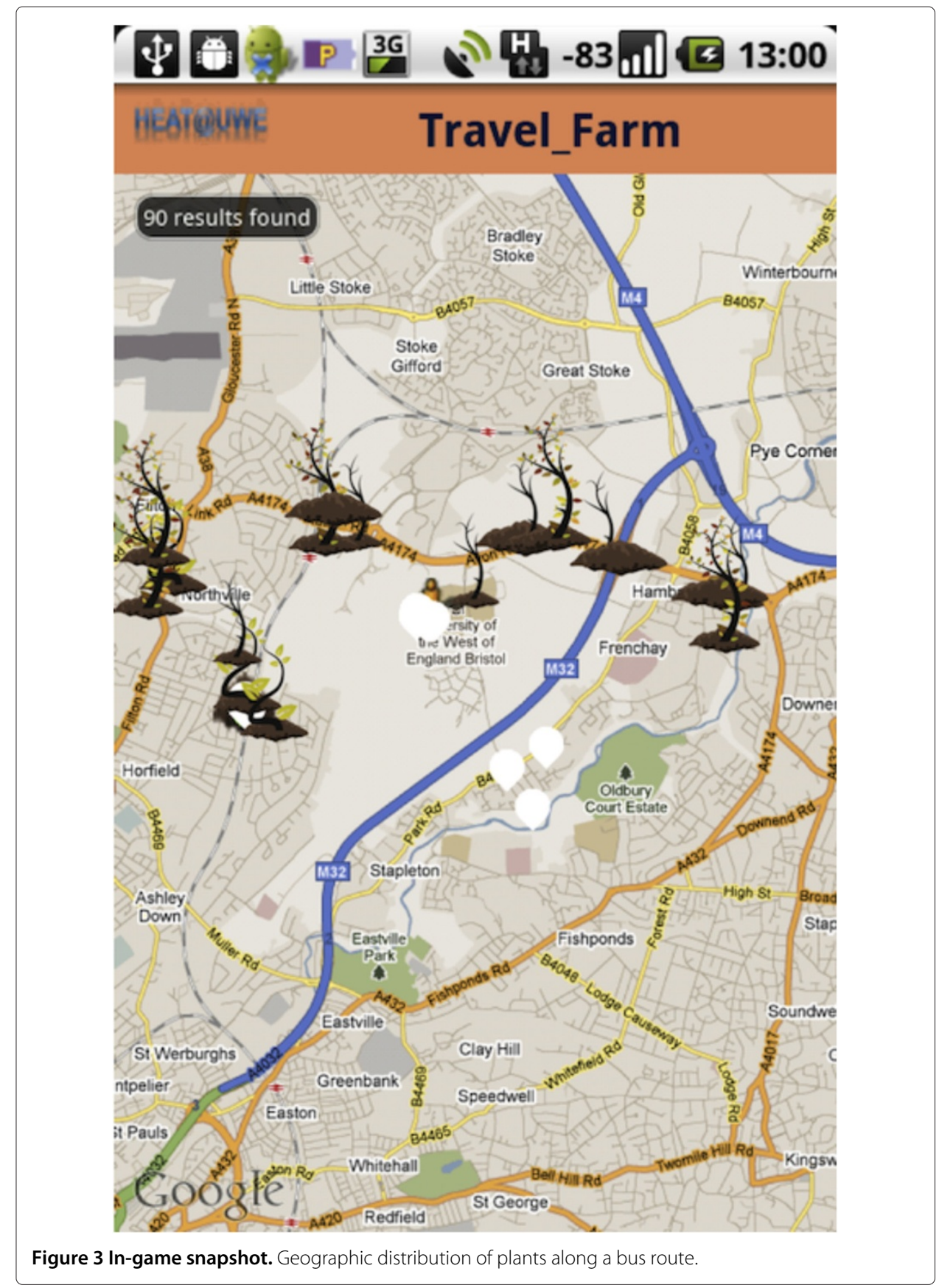

between movement and updating of the GPS data, so the application does not show an entirely accurate representation of where the user is. The variability of the bus speed and irregular starts and stops means that the users' location can not be corrected for statistically. This leads to a disrupted and broken experience.

\section{Game design recommendations}

Based on our experiences and original design directions, which intended the game to be both seamful and ambient, we list the following game design recommendations: 


\section{Seamful design}

Chalmers sets out a design strategy called Seamful Design [8] for dealing with ubiquitous computing applications. [8]. This involves designing to fit the inevitable problems such as sensor unreliability and connectivity loss into the game's design rather than assuming that the infrastructure is robust and reliable. This approach allows us to deal with the technical constraints rather than try to overcome them.

\section{Ambience}

Ambient games run in the background and don't require constant attention [9] and we envisaged a game that does not take over the travel experience, but works with the fractured nature of public transport. Research has shown that people on public transport tend not to focus on one task for the duration, and will probably engage in a number of activities on a journey [10]. This design direction is reinforced by the findings that extended use of AR on a bus may induce motion sickness, so a design constraint is to create a game that is only interacted with occasionally via the AR interface and functions primarily in the background.

\section{Dynamic generation of locations}

The game dynamically generates empty plots in places where the bus stops, and these will be maintained through planting and water. We have made this decision because of GPS lag, motion related sickness in the AR and the fact that the bus can speed by Layar locations making them difficult to interact with. The plots will be generated on either side of the bus so that there is always a plot outside the window that the player is seated nearest. This leads to a reduced need to point the phone camera at people to see plants that might located at the other side of the bus.

\section{Simple interaction mechanic}

The game interaction is designed to be simple as the game is intended to be ambient, and not distract from other activities on the bus, or simply the enjoyment of the journey. The system is also limited in the types and amount of interaction that can be achieved via Layar. So we will use an interaction that is similar to the 'check-in' mechanic used in location based services such as Foursquare (www.foursquare. com). The AR interface will present the user with icons or objects that can be interacted with a 'one-click' manner. The player's only decision will be to interact or not.

\section{Conclusion}

Discount usability techniques and early stage testing have delivered a variety of insights, which have impacted the game design. The contextual issues of motion sickness, embarrassment around camera use, usability problems and application aesthetics can be addressed through simple, seamful and ambient design. Even though we were aware of these design philosophies the findings presented in this paper have helped to reiterate the usefulness of these approaches for locative games.

\section{Endnote}

${ }^{a}$ This work is funded by the Bridging the Gaps in Health, Environment and Technology programme at the University of the West of England, which is an EPSRC project for kickstarting interdisciplinary research. 
Received: 18 December 2012 Accepted: 18 December 2012 Published: 29 January 2013

\section{References}

1. Layar Platform Overview (2012). [http://www.layar.com/documentation/browser/layar-platform-overview/]

2. Benyon D, Turner P, Turner S (2005) Designing interactive systems: People, activities, contexts, technologies. Addison-Wesley, Harlow, England

3. Nielsen J (2009) Discount Usability: 20 Years. Alertbox, September 14, 2009. http://www.useit.com/

4. Golding J (2006) Motion sickness susceptibility. Autonomic Neurosci 129(1-2): 67-76

5. Kennedy RS, Drexler J, Kennedy RC (2010) Research in visually induced motion sickness. Appl Ergon 41 (4): 494-503

6. Palen L, Dourish P (2003) Unpacking privacy for a networked world. In Proceedings of the SIGCHI conference on Human factors in computing systems. ACM, New York, NY, USA, pp. 129-136

7. Tamminen S, Oulasvirta A, Toiskallio K, Kankainen A (2004) Understanding mobile contexts. Personal Ubiquitous Comput 8(2): 135-143

8. Chalmers M, Galani A (2004) Seamful interweaving: heterogeneity in the theory and design of interactive systems. In 5th Conf. on Designing Interactive Systems. ACM, New York, NY, USA, pp. 243-252

9. Eyles M, Eglin R (2008) Ambient games, revealing a route to a world where work is play? Int J Comput Games Technol 2008: 1-7

10. Lyons G, Jain J, Holley D (2007) The use of travel time by rail passengers in Great Britain. Transportation Res Part A: Policy Pract 41: 107-120

doi:10.1186/2192-1121-2-1

Cite this article as: Dixon et al:: Experiences with AR plots: design issues and recommendations for augmented reality based mobile games. Communications in Mobile Computing 2013 2:1.

\section{Submit your manuscript to a SpringerOpen ${ }^{\odot}$ journal and benefit from:}

- Convenient online submission

Rigorous peer review

- Immediate publication on acceptance

- Open access: articles freely available online

- High visibility within the field

- Retaining the copyright to your article

Submit your next manuscript at $\boldsymbol{\triangleright}$ springeropen.com 